\title{
A study on organizational culture, structure and information technology as three KM enablers: A case study in five Iranian medical and healthcare research centers
}

\author{
Ali Khalghani ${ }^{\mathrm{a}^{*}}$, Hamideh Reshadatjoo ${ }^{\mathrm{b}}$ and Mahdi Iran-nejad-parizi ${ }^{\mathrm{c}}$
}

\begin{abstract}
${ }^{a}$ Management and Economics Faculty, Executive Management Department, Science and Research Branch of The Islamic Azad University, Tehran, Iran
${ }^{b}$ Management and Economics Faculty, Faculty Member of Tourism Management Department, Science and Research Branch of the Islamic Azad University, Tehran, Iran

${ }^{c}$ Management and Economics Faculty, Faculty Member of Executive Management Department, Science and Research Branch of the Islamic Azad University, Tehran, Iran

\section{H R O N I C L E}

Article history:

Received July 12, 2012

Received in revised format

29 October 2012

Accepted 15 November 2012

Available online

November 172012

Keywords:

Knowledge management

Organizational culture

Organizational structure

Information technology

Effectiveness A B S T R A C T

This study investigates organizational structure, culture, and information technology as knowledge management (KM) infrastructural capabilities, and compares their significance and status quo in five medical research centers in Tehran, Iran. Objectives of this research were pursued by employing two statistical methods, regression analysis and Friedman test. Included in the study were 135 people (researchers and support staff) from five medical and healthcare research centers of Tehran. A survey questionnaire including 23 questions was utilized to examine organizational structure, culture and information technology indicators. And another 12 questions examined KM effectiveness. The Friedman test indicated that in terms of their status quo, the three studied KM enablers are at different conditions, with organizational culture having the best (mean rank=1.79) and IT the worst (mean rank=2.14) status. Moreover, it was revealed by regression analysis that organizational structure is believed to have the most significant impact (Beta=0.397) on the effectiveness of knowledge management initiatives, while information technology gained the least perceived impact $($ Beta $=0.176)$.
\end{abstract}

C) 2013 Growing Science Ltd. All rights reserved.

\section{Introduction}

Knowledge Management (KM) in healthcare is normally considered as the confluence of formal methodologies and techniques to facilitate creation, identification, acquisition, development, preservation, dissemination and finally utilization of the different aspects of a healthcare enterprise's knowledge assets(Abidi, 2001).

*Corresponding author. Tel.: +98 912 5486052; fax: +98 2188578767

E-mail addresses: ali.khalghani@gmail.com (A. Khalghani) 
If organizational knowledge is to be implemented in an efficient way, relevant knowledge management strategies must be acquired. For this purpose, environmental factors, which act as KM infrastructures must be recognized and their conditions and significances must be taken into account for effective implementation of KM. There are normally three key infrastructures including technical, structural, and cultural, enable maximization of social capital (Gold et al., 2001). Organizational structure may encourage or inhibit $\mathrm{KM}$ and centralization and formalization are key variables underlying the structural construct. Moreover, they have recognizable impacts on KM within organizations (Lee \& Choi, 2003).

Organizational culture has been recognized by various research studies as KM enabler. Culture is considered as a set of values, norms, guiding beliefs, and understandings shared by members of an organization and taught to new members as the correct method to think, feel, and behave (Daft, 2010). Organizational culture must help people create and share knowledge, for instance, a renowned KM cultural slogan is "knowledge sharing is power." Information technology (IT) could be considered as a tool for saving, organizing and dissipating organizational knowledge. Therefore, its primary role goes beyond merely making information available. IT is essential for supporting KM throughout its process of acquiring, validating, storing, organizing, dissipating, and applying knowledge. During the past few decades, science in medical and healthcare has witnessed a growing boom and this field is becoming more knowledge intensive day after day. According to international statistics, one third of a physician's time is spent on analyzing information and creating knowledge, and the sum of medical knowledge is quadrupled during his or her lifetime (Heathfield \& Louw, 1999a). Taking into consideration the relative importance of knowledge in healthcare and medicine, one can understand the significance of KM in this sector.

The primary purpose of this study is to identify:

1. Which of the three mentioned enablers has a more noticeable impact on KM effectiveness in Iranian medicine and healthcare centers?

2. Which has been given more attention up until now?

3. and finally to compare the two outcomes.

For the first cause, regression analysis was utilized, and Friedman test was employed to answer the second question. The study was carried out in five medical research centers of Tehran, Iran. The total sum of participants, including researchers and support staff of the five centers, was 135 people. A survey questionnaire including 23 questions was utilized to investigate organizational structure, culture and information technology indicators and another 12 questions examined KM effectiveness. We first look through background associated with studies around the three mentioned enablers. Next, research methodology will be stated and statistical experiments' results will be illustrated. To conclude, the results will be discussed and suggestions will be given.

\section{Theoretical Background}

\subsection{Organizational Culture}

Knowledge is a knowledge-workers most valuable asset. Therefore, his or her approach to how this asset could be secured or invested is vital for the success of a KM program. Elements of organizational culture play significant role in the formation of an overall approach among employees in general and knowledge workers in particular. Culture appears to be a common enabler of KM in several research studies (Vittal \& Shivraj, 2010). Organizational culture is a complex entity of values, beliefs, behavior models, and symbols (Ho, 2009), shared among members of an organization. A research study by Gold et al. (2001), involving around 300 senior executives, revealed that an information-sharing culture was critical for effective KM. Organization culture, which encourages open and transparent 
communication among the employees of the organization would lead to increased collaboration and knowledge sharing at hierarchical levels of the organization, which leads to knowledge sharing, increased communication with the aid of standard processes, and technology infrastructure make it easy and enhance collaboration (Vittal \& Shivraj, 2010). Such employee interactions ought to be supported in both formal and informal manners (Gold et al., 2001). King (2008) listed four methods that organizational cultures (and subcultures) can impact KM. King explained that culture includes shapes assumptions about which knowledge is important, mediates the relationships between organizational and individual knowledge, creates a context for social interaction and shapes processes for the creation and adoption of new knowledge (King, 2008; Sin et al., 2009).

Lee and Choi (2003) addressed collaboration, trust and learning as indicators of organizational culture. Lack of "ask why" thinking, lack of trust (Kothar et al., 2011; Nicolini, et al., 2008b), and not being open to sharing knowledge and information such as "lessons learned" can impede KM efforts (Kothar et al., 2011; Nidumolu et al., 2001; Yeung et al., 2007). Moreover, organizational culture should have several components with regard to knowledge: (1) people have positive orientation to knowledge, (2) people are not inhibited in sharing knowledge, and (3) knowledge management project fits with the existing culture (Lee \& Choi, 2003; Sin et al., 2009). In addition, organization's formal statement should endorse and encourage KM activities (Gold et al., 2001). Also, clearly stating organizational vision and values, including the role of knowledge in achieving overall goals could support the organization's knowledge culture (Gold et al., 2001). Likewise, gaining commitment for a KM initiative requires support from senior management (Bishop et al., 2008). Managerial support should not only include allocation of enough resources and funds but must also take into account monitoring of organizational knowledge, and the organization's KM processes (Fahey \& Prusak, 1998; Gold et al., 2001). It is a long-term, sustainable commitment for changing the culture of health care to become more collaborative, more transparent, and more proactive (Guptill, 2005). Organizations that have shared common values and culture have an advantage when implementing a knowledge management system (Kothar et al., 2011; Nicolini et al., 2008b). There is also a need to be a 'knowledge creating and sharing culture, with trust and openness at the organization's core (Kothar et al., 2011).

\subsection{Organizational Structure}

The routs in which knowledge flows in the organization, and the lines through which people are connected, have an immediate impact on the effectiveness of the organization's KM initiative. Moreover, $\mathrm{KM}$ is an ongoing program, which requires continuous planning, direction, supervision and support. Thus, it is important for the organization to maintain an appropriate structure in place, if it is to have a constantly working KM program.

As Daft (2010) suggests, the definition of organizational structure has three components,

- The organizational structure designates the formal reporting relationships. It prescribes the levels of hierarchy the organization would have and the span of control for each level.

- The organizational structure prescribes the grouping of organizational members into departments and departments into an organization.

- The organizational structure determines the systems for coordination, communication and integration of efforts made by organizational members across the organization.

Organizational structure is very much associated with organizational culture and structures and can facilitate collaboration (Kimble \& Bourdon, 2008; Kothar et al., 2011). A structure which supports interpersonal interactions and eases face-to-face contacts could facilitate the organization's KM initiatives. Some authors recommended that organizations may need a whole new organizational 
structure, which would have conventional structures transformed to support a knowledge culture (Dwivedi et al., 2005; Kothar et al., 2011; Oliver \& Kandadi, 2006). The approach to KM ought be holistic with relatively flexible structures, and adaptable to the business environment changes (Kothar et al., 2011; Plessis, 2007). Some organizations may even require a chief knowledge officer (CKO) as head of the KM office devoted to KM initiatives.

Oliver and Kandadi recommended allocating suitable amount of time for employees' learning, collaboration, knowledge creation, and sharing activities as a fundamental structural consideration (Kothar et al., 2011; Oliver \& Kandadi, 2006). Research has disclosed that there could be some value in having a venue, or a social space, which enables and encourages knowledge sharing to take place (Abidi et al., 2005; Falkman et al., 2005; Kothar et al., 2011; Quinlan, 2009). the increased flexibility in an organizational structure can result in increased creation of knowledge (Lee \& Choi, 2003). On the contrary, A top down approach (Kothar et al., 2011; Lowe \& McIntosh, 2007) and separate departments can hurdle the effectiveness of a KM program (Hahn et al., 2005; Yeh et al., 2006a). in addition, Bishop et al. (2008) pointed out organizational structures as a reason for KM failure. Also, Damanpour et al. (1991) believed low formalization permits openness and variation, which encourage new ideas and behaviors ( Lee \& Choi, 2003). Moreover, Lee and Choei (2003) established a negative relationship between centralization, as a structural factor, and knowledge creation process while they could not prove a significant impact of formalization and knowledge creation (Lee \& Choi, 2003). O'Dell and Grayson (1999) agreed that an incentive system could motivate employees to work on KM in order to get rewards from knowledge creation, knowledge sharing and cross-department cooperation (Ho, 2009; O’Dell \& Grayson, 1998). Ho (2009) concluded that an organizational structure should incorporate an incentive system in KM.

\subsection{Information Technology}

Alavi and Leidner (2001) and Fairuz et al. (2008) all agreed that information technology (IT) plays an important role in supporting the organizational knowledge process. IT is tightly connected to KM because it helps distribute structural knowledge vertically and horizontally, as well as makes it easily searched and utilized. IT from a KM enabler perspective is the fundamental building block, which supports and coordinates KM, which among others include database, knowledge platform, performance evaluation management system, and integrated performance support system, etc. (Sin et al., 2009; Yeh et al., 2006b). IT can support information acquisition, process improvement, and knowledge storage. Employees can therefore work with KM conveniently. It also encourages employees to utilize the IT search function, incorporate and systematically store knowledge for their own implementation (Ho, 2009). IT competency also include an indirect impact on KM by facilitating the development of organizational structures, which favor the development and expansion of knowledge (López et al., 2009).

In healthcare also IT infrastructure has been considered as the groundwork for the implementation of KM practices and tools (Bordoloi \& Islam, 2012; Cain, Rodman, Sanfilippo, \& Kroll, 2005; Davis et al., 2009; Gray \& Lusignan, 1999). Using technology systems (and communication technologies) is a primary element, which may be implemented into KM initiatives. While details of each technical system vary, the overarching purpose of technology systems is to organize, distribute or codify and maintain knowledge based resource (Kothar et al., 2011; Massey et al., 2002). Alavi and Leidner (2001) insist that any progress in KM has only been due to stimuli by IT developments (Alavi \& Leidner, 2001). Accordingly, the predominant concentration of various KM strategies is on technology and management of explicit and tacit forms of knowledge (Kothar et al., 2011). Thus, IT plays an essential role in implementing KM. Yu et al. (2007) believed the quality of the IT tools, which measured in terms of response time, reliability, ease of use, etc. plays essential role on the implementation of KM system. They explained that if the quality did not satisfy the users' expectations, then that system would not only be deserted by the users but also it could fail to improve 
organizational performance. On the other hand, an easy-to-use, easy-to-access, responsive, and reliable system is able to enhance the process and outcomes of end users' knowledge creation, sharing, and utilization (Sin et al., 2009; Yu et al., 2007).

Despite the connection of KM to IT, one may not be satisfied by possessing apt IT infrastructure and merely implementing a KM system (KMS). Proper training of organization members and communication of the importance of utilizing the KMS throughout the organization are necessary for the success of the KM program. In addition to the conventional techniques, which save and share explicit knowledge, modern methods in which tacit knowledge is acquired and transferred must be taken into consideration, since the most valuable chunk of knowledge cannot be easily codified. Desouza (2003) stated that KM systems should encourage dialogue among individuals rather than just point to repositories. He asserted that it was nearly impossible to capture all expertise in databases, thus technology must move away from this goal and foster communication (Desouza, 2003; Sin et al., 2009). All being said, IT is only a KM facilitator, key to implementing knowledge management are the members of the organization.

\subsection{Importance of Knowledge Management in Healthcare Industry}

Due to the steady growth in healthcare sciences, healthcare has approached a stage wherein individual healthcare professionals could no longer keep track of the vast amount of scientific knowledge, which is associated with their clinical practice (Bordoloi \& Islam, 2012; Gray \& Lusignan, 1999; Heathfield \& Louw, 1999b; Nicolini et al., 2008b). The nature of knowledge in healthcare is such that it could be distributed and fragmented across organizational and professional boundaries (Bordoloi \& Islam, 2012; Gray \& Lusignan, 1999; Heathfield \& Louw, 1999b; Nicolini et al., 2008a). The necessity of $\mathrm{KM}$ in healthcare is due to the fact that healthcare professionals have encountered a paradox and they are overwhelmed with information but cannot choose a particular piece of information when and where they need it (Bordoloi \& Islam, 2012; Gray \& Lusignan, 1999).

Sheffield (2008) stated that KM was systemically more complex in healthcare because the three domain of knowledge creation, knowledge normalization and knowledge application correspond to three KM perspectives i.e., personal values, social norms and objective facts, respectively, which have inherent tension between and within them (Guptill, 2005; Sheffield, 2008). KM research in healthcare over the years has focused mainly on: the nature of knowledge in the healthcare sector, the type of KM tools and initiatives, which are suitable for the healthcare sector, and the barriers and enablers for adoption of KM practices (Bordoloi \& Islam, 2012; Nicolini et al., 2008b).

Interest in KM has increased in fields outside of business, particularly in health care, where health practitioners are beginning to recognize the potential of embedding KM concepts in their own practices and organizations (Kothar et al., 2011; Nicolini et al., 2008b). However, KM is not a short term quick fix. It is a long-term, sustainable commitment for changing the culture of health care to become more collaborative, more transparent, and more proactive. KM, implemented well, will transform the health care delivery system over the next few decades, into a more cost-effective, erroraverse, and accountable public resource (Guptill, 2005).

$\mathrm{KM}$ as a paradigm in healthcare has been quite new and there are only a few researches to "guide academic and organizational stakeholders" (Bordoloi \& Islam, 2012; Dwivedi et al., 2005). This is even more evident in Iranian healthcare industry where professionals in this field are less familiar with KM concepts. Therefore, this research aims to study the three fundamental capabilities of KM in Iran's healthcare industry. Also, overall KM effectiveness was investigated, regardless of the organization having a visible KM program or not. For this purpose, five medical and healthcare research centers have been chosen; as researchers believe that at this state research centers are more qualified for such inquiries. 


\section{Methodology}

\subsection{Sample selection and data collection}

Included in the study were 135 people (researchers and support staff) from five medical research centers of Tehran. A survey questionnaire including 23 questions was utilized to examine organizational structure, culture and information technology indicators and another 12-question questionnaire examined KM effectiveness. Survey questions were designed by taking into account factors elicited from the literature for each variable. For the purpose of this study, the researchers have taken into consideration the following organizational knowledge culture factors:

- The common understanding of the significance of knowledge to organization success among members of the organization.

- Organization members' awareness of the importance of sharing and distributing knowledge, and their willingness and commitment to engage in such activities.

- The value of on-the-job training and individual expertise.

- Encouragement to establish intergroup and intra-group interactions.

- Clarity of organizational vision, goals and values and the role of knowledge emphasized in organization's statements.

- Managerial support of KM initiatives

Also, for the sake of this study, researchers have investigated the following IT factors:

- Availability of internet access and its quality

- Availability of a standard method in which reports and other organizational documents are fixed and stored

- Availability of a knowledge repository and its maintenance

- Availability of a search engine for organizational knowledge and its quality and ease of use

- Organization members' tendency to make use of information technology for their professional requirements.

In addition, the following structural factors have been taken into account in this study:

- The availability of space and time for members to interact, collaborate and learn.

- Centralization_ locus of decision authority and control within an organizational entity (Lee \& Choi, 2003).

- Formalization the degree to which decisions and working relationships are governed by formal rules, standard policies, and procedures (Lee \& Choi, 2003).

- Incorporation of an incentive system in KM.

- Structural support of intergroup and intra-group interactions.

- Managerial involvement in the KM program.

Finally, the second questionnaire evaluated KM effectiveness using these measures:

- Respondents' perception of ease of access to knowledge requirements

- Respondents' perception of flow of knowledge throughout the organization

- Organization of information and knowledge

- Collaboration among individuals and groups

- Pace of responsiveness

- Increasing innovation

- Quality of service and customer satisfaction 


\subsection{Validity and Reliability test}

Validity of the questionnaires was tested through interviewing experts and asking for their consultation. Reliability was proved through Cronbach's alpha reliability test. Tables 1 and 2 show Reliability statistics for the two questionnaires.

Table 1

Reliability statistics for enablers' questionnaire
Table 2

Reliability statistics KM effectiveness questionnaire

\begin{tabular}{ccccc}
\cline { 5 - 6 } \cline { 5 - 6 } Cronbach's Alpha & N of Items & & Cronbach's Alpha & N of Items \\
\hline .895 & 48 & & .810 & 12 \\
\hline
\end{tabular}

\subsection{Data analysis}

Objectives of this research were pursued by employing two statistical methods, regression analysis and Friedman test. Regression analysis measured the changes of the dependant variable, KM effectiveness, against independent variables organizational culture, structure, and information technology. Thus, it helped to understand which of the three independent variables has a more noticeable impact on KM effectiveness. Friedman test on the other hand, ranked the three independent variables in terms of their current state in the research centers.

\subsubsection{Application of the Friedman test for Ranking the Status Quo of the Three KM Enablers:}

Survey questions where designed to inspect the current state of each variable from a respondent's point of view. Hence, researchers could employ Friedman test to rank the current condition of organizational culture, structure, and information technology. It should be noted that on the questionnaires' Likert scale used for the means of this research, \#1 was assigned to strongly agree, while \#5 was assigned to strongly disagree. In consequence, the higher the mean for a variable, demonstrates a worse status quo.

The Friedman test, which is a non-parametric statistical test equivalent to the parametric repeated measures ANOVA, is used to provide a statistical test of whether or not the means of several groups are all equal (Conover, 1980). Hence, it was applied in this study to compare the mean scores for the three KM enablers discussed herein. Research hypothesis are stated as:

$\mathrm{H}_{0}$ : By organization members' estimation, organizational culture, structure, and information technology as KM enablers' are all at an equal condition.

$\mathrm{H}_{1}$ : By organization members' estimation, organizational culture, structure, and information technology as KM enablers' are at different conditions.

\subsubsection{Application of regression analysis to Ranking the Three KM Enablers in terms of their impact on KM effectiveness:}

Regression analysis is a statistical tool for the investigation of relationships between variables. Usually, the investigator looks for ascertain the causal impact of one variable on another (Sykes, 1993). When investigating the impact of a number of predicator variables on a dependent variable, one may need to realize, which predicator best predicts the value of the dependant variable. For this purpose, standardized coefficients in the regression analysis, also referred to as beta coefficients (not to be confused with $\beta$, the population parameter), measure the change in the dependent variable (measured in standard deviations), which results from a one-standard-deviation change in the independent variables (Schroeder et al., 1986). Standard deviation measures the dispersion of the values of a specific variable about its mean. A one-standard-deviation change of predicator with a smaller standard deviation, results in a more noticeable change (bigger beta coefficient) in the value of 
the dependant variable. The change in the dependant variable due to a one-standard-deviation change of each predicator is: the dependant variable's standard deviation multiplied by the predicator's beta coefficient (Schroeder et al., 1986). The primary question in this study is whether organizational culture, structure or IT has the greater impact on KM effectiveness. That is, by how much KM effectiveness would change for a given change in organizational culture holding structure and IT constant, by how much it would change for a given change in organizational structure holding culture and IT constant, and by how much it would change for a given change in IT holding organizational culture and structure constant. From what was discussed, it could be concluded that if each of the KM enablers were to change one-standard-deviation, holding the other two constant, the change in KM effectiveness would be resulted from the its standard deviation multiplied by the changing enabler's beta coefficient.

\section{Results}

Results of this study include the ranking of status quo of the three KM enablers, obtained via the Friedman test, and ranking of the Three KM Enablers in terms of their impact on KM effectiveness, which was attained using the regression analysis.

\subsection{Ranking of the Status Quo of the Three KM Enablers Using the Friedman Test}

In order to examine the hypothesis, Friedman test was carried out in SPSS17. Test results are shown in Table 3, while Table 4 indicates the enablers' ranks. In Table 3, df stands for "degree of freedom" and Asymp. Sig. is an abbreviation for "asymptotic significance".

Table 3

Friedman test results

\begin{tabular}{ccc}
\hline Friedman test results & & \\
& N & 135 \\
& Chi-Square & 9.576 \\
& Df & 2 \\
& Asymp. Sig. & .008 \\
\hline
\end{tabular}

The Friedman test, which evaluated differences in medians among the three KM enablers, is significant $\chi_{2}(2, N=135)=9.576, p<.01$, indicating fair differences among the three enablers.

Table 4

KM enablers' status quo ranking in five Iranian medical and healthcare research centers

\begin{tabular}{rcc}
\hline Rank & KM enabler & Mean Rank \\
\hline 1 & Organizational Culture & 1.79 \\
2 & Organizational Structure & 2.07 \\
3 & Information Technology & 2.14 \\
\hline
\end{tabular}

Findings of this test illustrate that by organization members' estimation, organizational culture is in a better condition in comparison to the two other enablers, while information technology is in the poorest state.

4.2. Ranking of the Three KM Enablers in terms of their impact on KM effectiveness, using the Regression Analysis

Regression analysis was also carried out in SPSS17. Table 5 shows each variable's mean and standard deviation. 
Table 5

Research variables' mean and standard deviation

\begin{tabular}{lcccc}
\hline & $\begin{array}{l}\text { Information } \\
\text { technology }\end{array}$ & $\begin{array}{l}\text { Organizational } \\
\text { structure }\end{array}$ & $\begin{array}{l}\text { Organizational } \\
\text { culture }\end{array}$ & KM effectiveness \\
\hline $\begin{array}{l}\text { Number of valid } \\
\text { questionnaire s }\end{array}$ & 135 & 135 & 135 & 135 \\
Mean & 3.3852 & 3.3210 & 3.1885 & 3.3086 \\
Standard deviation & .68530 & .58930 & .61375 & .55717 \\
\hline
\end{tabular}

Table 6 shows the regression analysis coefficients, and table 7 demonstrates the change in KM effectiveness due to each enabler's one-standard-deviation change, holding the other two constant. In these tables, beta is the standardized coefficient, $t$ is the test statistic and sig. stands for "significance level".

Table 6

Regression analysis coefficients

\begin{tabular}{lccc}
\hline & Beta & $t$ & Sig. \\
\hline Constant & & 3.612 & .000 \\
Information technology & .176 & 2.438 & .016 \\
Organizational structure & .397 & 4.427 & .000 \\
Organizational culture & .259 & 3.162 & .002 \\
Dependant variable: organizational KM effectiveness & & & \\
\hline
\end{tabular}

Table 7

Change in KM effectiveness due to each enabler's one-standard-deviation change, holding the other two constant

\begin{tabular}{cccc}
\hline Predicator & $\begin{array}{c}\text { KM effectiveness Standard } \\
\text { deviation }(\sigma)\end{array}$ & Beta & $\begin{array}{c}\text { Change in KM effectiveness= } \\
\text { Beta } \times \sigma\end{array}$ \\
\hline Organizational structure & .55717 & .397 & .22119649 \\
Organizational culture & .55717 & .259 & .14430703 \\
Information technology & .55717 & .176 & .09806192 \\
\hline
\end{tabular}

Findings of the regression analysis indicate that in the five Iranian medical and healthcare centers studied herein, organizational structure best predicts KM effectiveness. After that stands organizational culture and the least influential amongst the three enablers in the studied centers is information technology.

\section{Conclusion}

As illustrates in Table 8, comparison of the results of the Friedman test and regression analysis suggest that although organizational culture is supportive of knowledge management initiatives, there is call for perfection of organizational structure, since regression analysis revealed its significant impact on KM effectiveness. Nevertheless, the fact that cultural acceptance of knowledge management exists among organization members could be a sign of hope for the success of KM initiatives.

\section{Table 8}

Comparison of the results of the Friedman test and regression analysis

Regression analysis: ranking of the three KM

enablers in terms of their impact on KM

effectiveness
Friedman test results: ranking of the three KM enablers status quo in the five research centers

$\begin{array}{cc}\text { Organizational structure } & \text { Organizational culture } \\ \text { Organizational culture } & \text { Organizational structure } \\ \text { Information technology } & \text { Information technology }\end{array}$


Information technology stands last in both regression analysis and Friedman test. The reason that it is located in the last position in Friedman test is obviously because of its status quo. However, information technology's low perceived impact indicated by the regression analysis may be due to its lack of familiarity amongst the respondents. That is, since generally the respondents have little experience of actually employing advanced IT tools for professional knowledge management purposes, they may not be aware of its advantages. It could be gathered that besides reinforcing IT infrastructure, necessary education should be included in the overall program.

In view of the fact that regarding the test results organizational structure has the highest impact on KM effectiveness compared to the other two enablers, and taking into account the theoretical background discussed earlier, it is suggested that interdivision links be improved and interaction among and inside groups be strengthened. Also, top-level management should become more involved in KM initiatives at the same time as centralization and formalization be decreased. In addition, incentive systems should be modified to support knowledge management activities.

It could be gathered from the results that in the studied centers, a structure that would facilitate connections inside and outside the organization and managerial support of KM initiatives through incentive and monitoring systems is crucial to their effectiveness. Also, a knowledge supporting culture in which managers and staff realize the role of knowledge flow in their organization success and are committed to applying and sharing knowledge in their daily activities is an important factor to the success of KM programs. In addition, information technology could support organizational knowledge management, but investing in it is only effective in the presence of the other two enablers.

As explained in theoretical background, quite a few researchers have studied knowledge management enablers, and specially the three pointed out in this study. However, none had done a comparative study on them; particularly, a comparison between enablers' status quo and their impact on KM effectiveness is unprecedented. Method and results of this study could help KM practitioners decide where the investment would have more effectiveness. Nevertheless, it is highly recommended that the same investigation be repeated in every specific environment, due to their specific characteristics.

\section{Acknowledgments}

The authors wish to express their gratitude to Mr. Mohsen Barouni for his comments and assistance in organizing this paper.

\section{References}

Abidi, S. S. R. (2001). Knowledge management in healthcare, towards 'knowledge-driven' decisionsupport services. International Journal of Medical Informatics, 63, 5-18.

Abidi, S. S. R., Yu-N, C., \& Curran, J. (2005). A knowledge creation info-structure to acquire and crystallize the tacit knowledge of health care experts. Information Technology in Biomedicine, 9(2), 193-204.

Alavi, M., \& Leidner, D. E. (2001). Knowledge management and knowledge management systems, conceptual foundations and research issues. MIS Quarterly, 25(1), 107-136.

Bishop, J., Bouchlaghem, D., Glass, J., \& Matsumoto, I. (2008). Ensuring the effectiveness of a knowledge management initiative. Journal of Knowledge Management, 12(4), 16-29.

Bordoloi, P., \& Islam, N. (2012). Knowledge Management Practices and Healthcare Delivery, A Contingency Framework. The Electronic Journal of Knowledge Management, 10(2), 110-120.

Cain, T., Rodman, R., Sanfilippo, F., \& Kroll, S. (2005). Managing Knowledge and Technology to Foster Innovation at The Ohio State University Medical Center, Academic Medicine, Vol. 80, 1026-1031.

Conover, W. J. (1980). Practical nonparametric statistics. New York, Wiley.

Daft, R. L. (2010). Organization Theory and Design (10 ed.), South-Western CENGAGE Learning. 
Damanpour, F. (1991). Organizational innovation, A meta-analysis of effects of determinants and moderators. Academy of Management Journal, 34(3), 555-590.

Davis, K., Doty, M., Shea, K., \& Stremikis, K. (2009). Health information technology and physician perceptions of quality of care and satisfaction. Health Policy, 90, 239-246.

Desouza, K. C. (2003). Barriers to Effective Use of Knowledge management Systems in Software Engineering. Communication of The ACM, 46(1), 99-101.

Dwivedi, A., Bali, R., \& Naguib, R. (2005). Knowledge Management for Healthcare, Using Information and Communication Technology for Decision Making. In J. M. Hershey (Ed.), Case Studies in Knowledge Management, 328-343, Idea Group Pub.

Fahey, L., \& Prusak, L. (1998). The Eleven Deadliest Sins Of Knowledge Management. California Management Review, 40(3).

Fairuz, A. R. M., Chong, S. C., \& Chew, K. W. (2008). Learning organisation disciplines and internet usage, an empirical study from Malaysia. International Journal of Management and Enterprise Development, 5(4), 462-483.

Falkman, G., Torgersson, O., Jontell, M., \& Gustafsson, M. (2005). SOMWeb-Towards an Infrastructure for Knowledge Sharing in Oral Medicine. Studies in Health Technology and Informatics 116, 527-532.

Gold, A. H., Malhotra, A., \& Segars, A. H. (2001). Knowledge management, an organizational capabilities perspective. Journal of Management Information Systems, 18(1), 185-214.

Gray, J., \& Lusignan, S. d. (1999). National electronic Library for Health (NeLH). BMJ, British Medical Journal, 319.

Guptill, J. (2005). Knowledge Management in Health Care. Journal of Health Care Finance, 31(3), $10-14$.

Hahn, T., Schmiedinger, B., \& Stephan, E. (2005). Supporting Research and Development Processes Using Knowledge Management Methods. In M. Jennex, \& P. Hershey (Eds.), Case Studies in Knowledge Management, 165-168, Idea Group Pub.

Heathfield, H., \& Louw, G. (1999). New Chalanges for Clinical Anformatics, Knowledge Management Tools. Health Informatics Journal, 5(2), 67-73.

Ho, C.-T. (2009). The relationship between knowledge management enablers and performance. Industrial Management \& Data Systems, 109(1), 98-117.

Kimble, C., \& Bourdon, I. (2008). Some success factors for the communal management of knowledge. International Journal of Information Management, 28(6), 461-467.

King, W. R. (2008). Questioning the conventional wisdom, culture-knowledge management relationships. Journal of Knowledge Management.47-35,(3)12,

Kothar, A., Hovanec, N., Hastie, R., \& Sibbald, S. (2011). Lessons from the business sector for successful knowledge management in health care, A systematic review, BMC Health Services Research.

Lee, H., \& Choi, B. (2003). Knowledge Management Enablers, Processes, and Organizational Performance, An Integrative View and Empirical Examination. Journal of Management Information Systems, 20(1), 179-228.

López, S. P., Peón, J. M. M., \& Ordás, C. J. V. (2009). Information Technology as an Enabler of Knowledge Management, An Empirical Analysis. Knowledge Management and Organizational Learning.

Lowe, A., \& McIntosh, A. (2007). Knowledge management in a New Zealand tree farming company, ambiguity and resistance to the 'technology solution'. Journal of Organizational Change Management, 20(4), 539-558.

Massey, A. P., Montoya-Weiss, M. M., \& O’Driscoll, T. M. (2002). Knowledge Management in Pursuit of Performance, Insights from Nortel Networks. MIS Quarterly, 26(3), 269-289.

Nicolini, D., Powell, J., Conville ,P., \& Martinez-Solano, L. (2008). Managing knowledge in the healthcare sector. A review. International Journal of Management Reviews, 10, 245-263. 
Nidumolu, S., Subramani, M., \& Aldrich, A. (2001). Situated learning and the situated knowledge web, Exploring the ground beneath knowledge management. Journal of Management Information Systems, 18(1), 115-150.

O'Dell, C., \& Grayson, J. (1998). If only we know what we know, identification and transfer of internal best practices. California Management Review, 40(3), 155-173.

Oliver, S., \& Kandadi, K. (2006). How to develop knowledge culture in organizations? A multiple case study of large distributed organizations. Journal of Knowledge Management, 10(4), 6-24.

Plessis, M. (2007). Knowledge management, what makes complex implementations successful? Journal of Knowledge Management, 11(2), 91.101-

Quinlan, E. (2009). The "actualities" of knowledge work, an institutional ethnography of multidisciplinary primary health care teams. Sociology of Health and Illness 31(5), 625-641.

Schroeder, L. D., Sjoquist, D. L., \& Stephan, P. E. (1986). Understanding Regression Analysis, An Introductory Guide, SAGE Publications Inc

Sheffield, J. (2008). Inquiry in health knowledge management. Journal of Knowledge Management, 12: $160-172$.

Sin, C. H., Goh, G. G. G., \& Eze, U. C. (2009). Knowledge Management Enablers Toward Successful New Product Development: A Case Study In A Semiconductor Manufacturing Firm. Journal of Knowledge Management Practice, 10(4), 16-32.

Sykes, A. O. (1993). An Introduction to Regression Analysis.

Vittal, S. A., \& Shivraj, K. 2010. Modeling enablers for successful KM implementation. Journal of Knowledge Management, 14(1), 100-113.

Yeh, Y., Lai, S., \& Ho, C. (2006). Knowledge management enablers: a case study Industrial Management \& Data Systems, 106(6), 793-810.

Yeung, A., Lai, K., \& International, R. Y. (2007). Organizational learning, innovativeness, and organizational performance: a qualitative investigation. Journal of Production Research, 45(11), 24-59.

Yu, S.-H., Kim, Y.-G., \& Kim, M.-Y. (2007). Do we know what really drives KM performance? Journal of Knowledge Management, 11(6), 39-53. 